\section{THE PERCY SLADEN TRUST EXPEDITION TO THE INDIAN OCEAN. FURTHER EXPLORATIONS. ${ }^{1}$}

TO complete the work of the above expedition I left in June last for the Seychelles, accompanied by $\mathrm{Mr}$. H. Scott and Mr. J. C. F. Fryer as naturalists. We arrived there on July 1o, but were unfortunately detained on Long Island, the quarantine station, for ten days. The time, however, was by no means wasted, as the island was fairly representative of low-country coco nut cultivation, and contained a fairly rich insect fauna, mainly of introduced species. We had boats also, and were thus enabled to examine the reefs in its vicinity, collecting particularly the sedentary organisms.

On July 23 I sent $\mathrm{Mr}$. Fryer to examine Bird and Dennis, two islands seventy miles to the north of Mahé, on the edge of the Seychelles Bank. He remained a fortnight on each, examining them in all their aspects. The former was barren, with a vast number of sea birds breeding upon it, while the latter was planted in coco nuts. Both proved to be formed entirely of coral material, rock and sand, and both were found to be gradually washing away into the sea. The surface reefs around them are insignificant, and they gave the impression of being the remains of reefs once widely extending along the north edge of the whole bank. On his return Mr. Fryer at once started down to visit the islands of Aldabra, Assumption, Cosmoledo, and Astove, among which he is to work for four months. These islands lie to the north-west of Madagascar, and due west of Farquhar Atoll, visited by the Sealark in 1905. Assumption and Aldabra form the most western group, the former being a crescent-shaped bank, $3^{\frac{1}{2}}$ miles long, and the latter a ring-shaped atoll, I9 miles long by 7 miles across, almost completely surrounded by land, with a shallow lagoon.

Astove and Cosmoledo form a second group, the former a ring-shaped atoll, 2 miles long, completely surrounded by land save for one passage to the south, and the latter an atoll, $9^{\frac{1}{2}}$ miles by 7 miles, lagoon 4 fathoms, ring much broken up, with eight main islands. Aldabra is well known as the home of gigantic land tortoises. Some rock from it in my possession contains abundant silica, a fact which makes the accompanying abstracts from Mr. Fryer's preliminary report on its adjacent islands of peculiar interest.

On July 24, accompanied by Mr. Scott, I went to Silhouette, the second highest island in the Seychelles, 2467 feet. We settled at 1600 feet, within the indigenous jungle, of which a square mile still exists. Here Mr. Scott remained until October $\mathrm{x}$, obtaining a rich collection of its insect fauna, which, allowing for the difference in the size and position of the islands, appeared to be to a large degree comparable in its nature to that of the Sandwich Islands. The island itself is about 12 square miles in extent, with rugged granite hills, and two bays with flats covered with coco nuts. These owe their existence to former fringing reefs, the level of the island having changed to the extent of at least 30 feet within comparatively recent times. The coco nut is grown up to 1200 feet, but the trees, as is also the case in Mahé, are infested with a fungoid disease, and do not bear well.

After a month in Silhouette I returned to Mahé, every part of which I visited in the ensuing seven weeks. For the most part I was occupied in examining its geographical teatures, rocks, reefs, and jungles, and in collecting its plants, of which I obtained upwards of 2000 sheets. I have little of general interest to add to my report in NaturE, January 25, 1906. Mahé showed the same change of level as Silhouette, and my former impression, that there might have been a more ancient elevation of about 200 feet, proved to be erroneous. Only about $2 \frac{1}{2}$ square miles of the indigenous iungle are now left, and that is being gradually affected by the reckless destruction of its larger trees. Mr. Scott is to collect its insects during the next four months, but it can scarcely be supposed that more than a small percentage of its indigenous fauna still manages to survive. This iungle area lies in the centre of the island, the north and south thirds of which,

1 For earlier reports see Nature, April 13, August 10, October 5, November 9 , December 21, 1905, and January 25, 1906. being almost completely deforested, have become physiologically dry, to the almost complete destruction of their indigenous flora and fauna. Much of the land, too has been destroved by cassava planting, which is followed on the steep hill-sides by the washing away of the soil, converting them into bare glacis.

\section{J. Stanley Groviner.}

Astove, where we arrived first, is an atoll about 2 miles long by $1 \frac{1}{2}$ miles broad; so far as I could tell it is entirely composed of elevatcd coral as a basis, with sand distributed in various places. The seaward beach in most parts is formed of sand, but in places coral rock forms small cliffs, showing very evident washing away. There is only one pass. This is narrow, and from the present rate of washing away must be of fairly recent date. On the westward side of the pass are "coral rock" cliffs, while on the east a good deal of piling up of big blocks has occurred. These blocks are all of coral rock, not dead corals. They appeared to have come partly from the present land (washed out) and partly from the reef, which, so far as I could see, was composed of coral rock only, and was not ordinary dead reef such as I saw at Bird Island, to the north of the Seychelles. The coral rock interested me very much. In places one could see regular fields of coral with all the corals in their natural positions, while here and there are small holes, 5 feet to 6 feet deep, with sides all encrusted with corals exactly as they grew. There was absolutely no question of piling up. The whole place is evidently exactly as it was underneath the sea. In parts of the island the corals have been more "metamorphosed" into rock (not retaining their original structure), but I could trace no correlation between the occurrence of this rock and its position on the island. In the north of the island there are some dunes about 50 feet high, purely of wind formation. I dug a hole on. the landward side of one, and found guano underneath with a sort of shingle one, and think the north-west monsoon must have been much stronger once, or cyclones more frequent, to have driven this shingle inland,

The lagoon is very shallow: bottom of fine coral (?) mud, which makes the whole lagoon white, and forms a froth all round the shore. There are one or two small islands near the pass. There will probably be two more "passes" formed soon, one to the N.N.E. and another to the S.E. The reef to the west is sandy, with little living coral. It falls directly to " no bottom" without any slope, so that a ship cannot anchor, but is moored by lines to the reef. I searched the reef opposite the pass, but found no living corals, only a piece or two of recently killed coral thrown up. As I have said before, it is rock, and not reef. In one place it drops to the sea in terraces, forming small waterfalls as the tide goes out.

The next island we went to, Cosmoledo, represents further stage in the Astove condition. There are only a few islands left. The settlement is on Menai, with a fishing station on Wizard. The rock is the same as at Astove, but naturally there is very much more sand. All round the reef the remains of islands stick up like rock mushrooms. On Menai Island there is a mangrove swamp on the lagoon side, trees mostly small, as the larger have been cut for their bark, used for tanning. There is a sand-dune, with some very old Casuarina. Everything was very dead and burnt up, and not nearly so attractive as at Astove. I went also to Wizard, Goëlette, and North East Islands. Wizard is very sandy, but has the distinction of having three good wells. I got a positive measure as to the rate of erosion, 15 yards having gone in the last fifteen years (measured by Spur's old house, which is now in the sea). Goëlette is of no interest except as containing some guano; North-East Island I only stayed on for a short time; all the guano has been dug, and is now being taken to the Cape. I caught a large lizard there, which occurs on none of the other islands, but it seems to me to be only a variety of the universal small one We had wretched weather, very squally, and I seem to have spent most of my time in a whale-boat trying to get to somewhere.

The next island, Assumption, is the most interesting of the three; it is not an atoll, and the settlement is a new one, so that everything is untouched. The rock is 
the same as at the other islands, but is more changed, and possibly contains some mineral other than calcium. The most interesting feature was the presence of big pits, some very deep, all over the island. The rock seems to be honeycombed with holes, sometimes covered in and sometimes open through the falling in of the superficial layer. Further, in three of these pits I found mangroves growing, all of very great age. Two contain Brugiera and onc Ceriops. I thoroughly explored all these holes, digging where possible. In one mangrove hole the bottom was guano; I dug 18 inches, but water came in so quickly that we could go no further. The water was salt. The crowbar showed at least 5 feet more "guano mud." The hole was about 8 feet deep, and so there must have been at least I3 feet altogether. There was plenty of mangrove (Brugiera) seed, but very few young trees. This hole was on the eastward side of the island, near the sea. In another hole, just west of the centre of the island, the trees were also Brugiera. This hole was very deep $(25$ feet to 30 feet), with pools of brackish water (undoubtedly. from the sea). Digging again was hopeless, and the crowbar found no bottom. I found some shells in the mangroves, most of which were dead. In another hole (north of the island) there were Ceriops trees. The hole was iz feet deep, the bottom wet and muddy, salt water standing on one side (and fluctuating with the tide). We tried digging here with more success, the water coming in from the sides, and not the bottom. We got down two holes ${ }_{5} 5$ feet, and then found a great lump of coral, which the crowbar broke off. The water got so high that I could not tell whether this was a coral lump tumbled off the walls and fallen by chance in a natural position, or whether it was the bottom of the hole. So I dug another hole, and at a depth of 6 feet came to a soft, white ooze rock; how much of it there was I do not know, as we could only grovel for bits broken off by the crowbar in 4 feet of mud and water. How the mangroves got into these pits I cannot imagine. There is certainly nothing more than a free percolation from the sea. The only suggestion I have is that there have been two elevations, and that after the first the island was only a foot or two out of the water, possibly with protecting sand round the edge, and that it was covered with mangroves.

In one hole $I$ found the remains of land tortoises, which are certainly extinct now. Is there any historical evidence? ${ }^{2}$ I send all I could find to try and ascertain the species, or rather to see if it is the same as the Aldabra one. I also send some things found by the manager in the guano which look like eggs of these tortoises. I heard that the same had been found also at Cosmoledo.

The deepest hole was 45 feet deep, and contained 23 feet of water, which in all cases was salt. I tried to think if a lagoon formation could take place this way, but do not quite see it yet. The holes are certainly increasing in size owing to erosion and weathering, but must at the same time get shallower. There are some high dunes, 70 feet, at the south-east; wherever there is sand on the east of an island a dune is formed; as a rule, however, this side is bare rock, as the sea is very heavy, and keeps it clear of sand.

The vegetation of Assumption differs slightly from that of the other islands in that there are numbers of tanghain (Euphorbia abbotti) and la fouche (Ficus) trees, which give the land a different appearance. Of animals, I caught two species of bat, from which I got some Nycterobia.

\section{J. C. F. FRYER}

\section{THE ORIGIN OF THE POTATO.}

$\mathrm{T}$ is a curious fact that the origin of the potato of commerce, Solanum tuberosum, that is, the wild species from whence it was derived by selective cultivation, has hitherto baffled research, none of the many wild species of that genus agreeing sufficiently closely in character to be identified with any of the innumerable varieties existing. This in itself might have been of little

$$
1 \text { No.-J. S. G. }
$$

No. 2042, VOL. 79] importance had not the outbreak of the potato disease in the last century suggested the wisdom of finding the original wild species, and by crossing it with the cultivated forms, of infusing fresh vigour into the latter, and thus to some extent fortify them against that destructive plague. To this end Mr. A. W. Sutton, of Reading, collected as many of the wild species as he could from the native habitats in Chili and Peru, and also from outside sources in North America and elsewhere, but none of these could be accepted as the parental form of the potato of commerce, and though many experiments were made in the way of hybridisation, the results were entirely negative so far as obtaining an improved strain was concerned, and the trials consequently ceased.

A fresh impulse was given to Mr. Sutton's researches by the alleged appearance in France of a "sport" from a wild species known as Solanum commersonii, which "sport" was declared to be fully equal to good varieties of the potato of commerce, though it had arisen, as the presumed raiser asserted, from a tuber of the wild species named. Not only, however, did this "sport" resemble closely a cultivated potato in all its characters, but investigation proved to all practical potato growers and experts that it was identical with a well-known variety, and that, in point of fact, it must have originated from a tuber or part of a tuber of that variety which had accidentally been in the soil in association with the wild tubers. The renewed research to establish this fact had, however, the result of re-directing Mr. Sutton's attention to another wild species called S. etuberosum, which had been grown in Mr. Sutton's ground for some twenty years, but which until Igo6 had not been observed to produce any seedberrics, and had consequently not lent itself to seminal culture, but during that period its tubers, originally small and about the size of marbles, but white and edible, had increased to 2 inches to 3 inches in diameter, and when cooked resembled closely an ordinary potato. In 1906, however, one seedberry was observed, and the opportunity of sowing was immediately seized upon. Hitherto all the recognised wild species when sown yielded true offspring, that is, no variation at all was observed, and Mr. Sutton's surprise may therefore be judged when the twenty plants produced from this seedberry were not only of very varied character in foliage, flowers, and tubers, these last being of many colours and shapes, but they were diverse on precisely the lines of a batch of seedlings of the common potato, from which, indeed, they could not be discriminated even by an expert. The idea consequently arose that this might be due to cross-fertilisation with one of the ordinary potatoes in the vicinity, and though Mr. Sutton's experience led him to doubt this, he proceeded to check these results by a second sowing in 1908 from several seedberries which had been successfully self-fertilised by hand, and were consequently free from suspicion. The resulting plants, however, were equally diverse, and on the same lines. A second suggestion was then made that the parent plant, $S$. etuberosum, was not really a wild species, but an escape from cultivation; but here, apart from the original smallness of the tubers, the botanist steps in, for all the wild species examined have pollen grains of a symmetrically oval or elliptical shape, and $S$. etuberosum has them of same form, while all pollen grains examined of cultivated potatoes are extremely irregular in size and shape, and no true elliptical ones are seen. The true specific character of $S$. etuberosum is thus established, while the identity of its offspring with that of the commercial potato equally establishes the fact of its being the original wild species.

Finally, a most important economical fact remains to be mentioned. For more than twenty years $S$. etuberosum has entirely defied the potato disease in the Reading grounds, though year after year subjected to infection by closely adjacent plants. The result originally aimed at when the experiments commenced is thus more than achieved, since there is no necessity for cross-fertilising with the ordinary potato, which is susceptible to disease, and consequently we have all the vigour of the wild type without any taint whatever in the new strain of diseaseproof or disease-resisting potatoes which, it is hoped, has now appeared.

Chas. T. Druery. 